\title{
Pari passu: Historiografia e Ciência da Peste em Portugal (1832-2021)
}

\author{
Pari passu: Historiography and Science of the Plague in Portugal \\ $(1832-2021)$
}

André Filipe Oliveira da Silva, Universidade do Porto / CIDEHUS - Universidade de Évora (andre.f.oliveira.silva@gmail.com)

Resumo: A investigação histórica e a produção historiográfica devem tanto ao passado que estudam como ao presente que as produz. Dentro deste universo, a História da Ciência oferece exemplos valiosos da evolução paralela da ciência nas suas mais diversas dimensões e da leitura e interpretação do seu passado. No caso do estudo das epidemias históricas, a relação do que se sabe numa certa época com o que se escreve sobre as que a antecederam não só é evidente, como não pode ser esquecida quando se faz a história da própria historiografia. Neste breve artigo, proponho uma análise à evolução da historiografia portuguesa sobre epidemias medievais de peste, em particular a Peste Negra, paralela à do conhecimento que se tinha da doença em cada momento, tentando-se determinar a que ritmo os historiadores portugueses absorviam as novidades da ciência do seu tempo e as integravam nas suas próprias análises. Da teoria miasmática à definição da teoria microbiana das doenças, da descoberta da bactéria responsável pela doença (e, pouco depois, da transmissão vetorial), até à confirmação da identidade do agente patogénico em pandemias passadas, todas estas descobertas tiveram um impacto profundo na maneira como as pestes passadas eram estudadas e compreendidas. Cultivando uma relação simbiótica mais do que secular, as Ciências Naturais e da Vida, por um lado, e a História, por outro, seguem estabelecendo pontes que beneficiam ambas e que permitem a produção de conhecimento científico cada vez mais rigoroso, transversal e útil.

Palavras-chave: Historiografia, História da Medicina, Peste, Peste Negra, Diálogo Multidisciplinar

Abstract: Historical research and historiographical production have always been
strongly connected both with the past they study and with the present they are
produced in. Inside this universe, History of Science offers valuable examples of
parallel evolution of science in its most diverse dimensions and of the interpretation
of its past. Talking about the study of past epidemics, specifically, the relation
between what is known about a disease in a certain moment and what is written
about past occurrences of that disease is not just evident but cannot also be forgotten
when the history of that historiography is written. The aim of this brief paper is to 
analyse the evolution of Portuguese historiography about medieval plague epidemics, especially Black Death, confronting it with the evolution of the scientific knowledge about that disease throughout the decades and determining how fast did Portuguese historians integrate that knowledge in their own historical analysis. From miasmatical theory until the definition of microbial theory of diseases, from the discovery of the plague bacillus (and little after, the vectorial transmission) to the confirmation of the identity of plague bacteria as the responsible for Black Death, all these discoveries influenced the way past plagues were studied and understood. Cultivating a symbiotic relationship since a long time ago, Natural and Life Sciences, at one side, and History, at the other, move forward together, establishing bridges that benefit both and allow the production of a scientific knowledge progressively more rigorous, transversal and useful.

Keywords: Historiography, History of Medicine, Plague, Black Death, Multidisciplinary Dialogue

\section{Introdução}

O estado da arte da ciência num determinado momento é também um instantâneo do presente então vivido. A História da Ciência é, por isso e como todo o estudo do passado, uma súmula de presentes efémeros que se sucedem e estratificam irresistivelmente. Este breve artigo tem como objetivo fundamental analisar, por um lado, a forma como a comunidade científica portuguesa acompanhou e contribuiu para o conhecimento científico sobre uma doença específica, a peste, e, por outro, a maneira como os historiadores portugueses fizeram uso desses sucessivos presentes - os seus próprios - para construírem de forma mais fiel e rigorosa os passados que se acumulam. De que forma saber mais sobre uma doença no presente clarifica e torna mais atingível o conhecimento de fenómenos passados? De que maneira uma descoberta notável de 2011 pôde esclarecer um debate com décadas, confirmar a omnipresença secular de uma mesma infeção e partir para novos debates, novas questões, novos problemas? O que se deve esperar do diálogo multidisciplinar, entre ciências da vida e ciências humanas, com mútuo benefício e necessidade? Questões como estas podem orientar-nos na análise desses diversos presentes, situar-nos no nosso próprio e guiar-nos no apuramento de práticas e análises futuras.

Esta análise é feita a partir da perspetiva do historiador, enquanto produtor de conhecimento científico sobre o passado e espectador interventivo no desenvolvimento das ciências da vida que procuram reconstituir eventos pretéritos e estabelecer ligações entre a história natural e humana. O diálogo multidisciplinar é hoje um dos eixos fundamentais do desenvolvimento da ciência e do conhecimento. Não sendo um conceito novo, revestiu-se de uma nova urgência como contrapeso 
face à ultra-especialização que resulta, amiúde, num afunilamento restritivo e contraproducente. A escrita e o conhecimento da História, tal como a escrita e o conhecimento da Medicina, tiveram as suas primeiras manifestações formais na Antiguidade. Porém, a "cientificização" da História foi muito mais demorada, e apesar de toda a produção historiográfica levada a cabo ao longo dos séculos, foi preciso chegar ao advento do Período Contemporâneo para assistir à profissionalização da História, ao desenvolvimento de um método científico de investigação e produção de conhecimento do passado, e ao estabelecimento de cursos universitários que padronizassem práticas e estabelecessem comunidades de conhecimento cujos resultados passaram a estar ao alcance de um número cada vez maior de leitores, chegando em simultâneo a todos através de disciplinas dos cada vez mais frequentados níveis básicos de escolaridade.

Dentro deste universo vastíssimo, a peste, e a Peste Negra em concreto, constituem casos paradigmáticos. $O$ resgate da sua memória inaugurou a epidemiologia histórica na primeira metade do século XIX. A sua reemergência trouxe-a para a agenda das novas ciências da vida que se desenvolviam rapidamente na segunda metade de Oitocentos. O debate sobre a sua etiologia produziu os primeiros debates em larga escala envolvendo biólogos e historiadores. Enfim, as descobertas extraordinárias deste século, permitidas pelo desenvolvimento da paleogenómica e da arqueologia molecular, demonstraram que apenas o trabalho multidisciplinar poderá garantir avanços que poucos anos antes seriam ficção científica pura. O caso português, modesto quando comparado com outras realidades, merece atenção: é esse olhar que se desenvolverá adiante.

A bibliografia sobre a peste, sobre a sua história e a sua natureza, é incontável. Não se pretende, em momento algum, que esta pequena reflexão constitua uma enumeração exaustiva de literatura científica e historiográfica sobre o fenómeno, mesmo no caso português. Mais do que uma lista bibliométrica, pretende-se perceber como evolui este conhecimento, como ele chega e como é aproveitado em Portugal, constituindo apenas uma primeira aproximação a um campo muito vasto e ainda tão pouco explorado.

\section{Os miasmas do Oriente (1832-1894)}

Desde o seu estabelecimento, a História da Medicina foi essencialmente um labor de profissionais da cura. A evolução da medicina, motivada tanto pela experiência empírica como pela formação académica, nunca cessou. Apesar de existir uma sólida tradição de história médica, intimamente relacionada com o desenvolvimento de um pensamento médico e com a definição de uma identidade profissional (Grmek, 1995, p. 7-24), nem sempre a história das epidemias era um 
objeto de interesse. Muitas vezes, o foco recaía em certos autores e praticantes, e menos em fenómenos como as próprias doenças, estando as epidemias do passado reduzidas a listagens de eventos. Assim, no princípio do século XIX, as explicações científicas para a natureza das epidemias, das doenças que afetavam pessoas muito diferentes em simultâneo numa determinada área e que se iam movendo no território eram ainda largamente devedoras de teorias desenvolvidas desde a Antiguidade Clássica. Estas teorias, dominadas pela ideia da formação de miasmas que corrompiam o ar e provocavam o adoecimento de um grande número de indivíduos num mesmo local e com compleições muitos distintas, que a teoria humoral antiga e medieval (Rawcliffe, 2010, pp. 317-334) não decifrava, eram a melhor explicação até à descoberta dos agentes patogénicos, e resultavam de um processo de negociação intelectual, multissecular, entre as definições clássicas de saúde e a aparente irracionalidade dos fenómenos epidémicos (Pigeaud, 2017, pp. 15-27).

Em 1832, dá-se o princípio simbólico da historiografia moderna da Peste Negra, com a publicação do livro intitulado Der schwarze Tod im vierzehnten Jahrhundert: Nach den Quellen für Ärzte und gebildete Nichtärzte bearbeitet ${ }^{1}$, da autoria de Justus Friedrich Karl Hecker. Esta obra recupera uma expressão usada por algumas crónicas modernas em línguas germânicas para se referirem à peste de meados do século XIV (morte negra), tornando-a canónica. Este ponto de partida da historiografia da Peste Negra não é uma recuperação de memória acidental ou inocente: Hecker, médico e professor de História da Medicina na Universidade de Berlim, estuda a Peste Negra durante a segunda pandemia de cólera (1826-1837), a primeira que afetou a Europa e produziu um impacto profundo na opinião pública e no imaginário coletivo do seu tempo (Slack 2012, p. 43). Para os eruditos europeus do final do século XVIII e do princípio do século XIX, a peste parecia distante, e o resgaste da sua história e da sua memória era mais metafórico do que comparativo no colérico século XIX. Antes do surgimento destes novos fenómenos pandémicos oitocentistas, a peste parecia ser já apenas uma curiosidade na Europa Ocidental: em 1769, por exemplo, um médico francês dizia não conhecer nem reconhecer aquela peste descrita pelos autores antigos (Biraben, 1989, pp. 367374), apenas meio século após a devastadora Peste de Marselha (1720-22) e numa altura em que ainda se registavam surtos esporádicos em alguns portos europeus mediterrânicos (e que se prolongarão ainda até ao século XIX (Moll, Salas Vives \& Pujadas-Mora, 2017)).

Portugal não vivia alheio a esta realidade, e um nome sobrepõe-se a todos entre aqueles que se debruçaram sobre as epidemias passadas que varreram o Ocidente

\footnotetext{
${ }^{1}$ Numa tradução livre em português: "A "Morte Negra" no Século XIV: a partir das fontes para médicos e não-médicos instruídos".
} 
Peninsular: António da Cunha Vieira de Meireles. Este médico e lente coimbrão publicou umas Memorias da Epidemiologia Portugueza (Meireles, 1866) que se tornaram a obra de referência sobre o assunto ao longo de mais de um século. Muitos historiadores e médicos interessados na História recorreram a esta obra para aproveitar a lista cronológica de epidemias que teriam assolado Portugal ao longo dos séculos. A abordagem de Vieira de Meireles era clássica. A sua leitura "nosogeográfica" bebia muitíssimo da medicina "metereológica" hipocrática, explicando doenças que afetavam grandes populações (muitas delas hoje definidas como infeciosas, outras não, como as avitaminoses) através das características dos climas e solos de certos territórios (Silva, 2021, pp. 51-53).

Curiosamente, este ciclo cessa com o lançamento de uma obra historiográfica marcante sobre a Peste Negra. Trata-se da primeira edição da obra de Francis Aidan Gasquet, monge inglês e futuro cardeal e Bibliotecário e Arquivista da Santa Igreja de Roma, intitulada The black death of 1348 and 1349 [1893], e que seria um exemplo perfeito de uma história da Peste Negra pintada em tons apocalípticos, pertencente àquilo que Paul Slack (2012, p. 42-44) designa como uma historiografia "gótica", em alusão à literatura coeva da Inglaterra Vitoriana. Como se verá, contudo, o encerramento de um ciclo na ciência da peste não provocará a obsolescência precoce desta obra, incluindo em Portugal. Porém, meses depois da sua publicação original, dá-se uma verdadeira revolução no conhecimento sobre a doença e o agente responsável por ela.

A historiografia que se vinha construindo sobre a Peste Negra, escrita em tons expressionistas, não só não era desmontada pelas novidades, como podia acolher muito bem a imagem de uma doença transportada por ratos e transmitida por pulgas que abandonavam os cadáveres frios dos roedores. A etiologia da doença não era ainda uma questão central na reconstituição do evento, sendo os valores de mortalidade e o conjunto das consequências demográficas, mentais e culturais de curta, média e longa duração o que realmente interessava a estes autores. Prova disso mesmo é a ausência de alterações substanciais quando uma segunda edição é lançada, em 1908: o autor faz referência à descoberta do bacilo no prefácio especialmente preparado para essa edição, mas mais nada se altera (Kriehn, 1909). Não era ainda tempo de ciência e história da peste caminharem paralelamente.

Uma história da Peste e o (aparente) silêncio dos historiadores (1894-1974)

A mudança do paradigma geral sobre a origem das doenças que hoje conhecemos como infeciosas fez-se com o desenvolvimento da teórica microbiana que teve em Louis Pasteur o seu principal contribuidor. Porém, cada doença teve 
de aguardar o apuramento da sua etiologia para ser classificada como infeciosa e, dentro destas, de que tipo.

A eclosão da chamada Terceira Pandemia de Peste, um novo ciclo que sucede (e se sobrepõe, em algumas regiões) à Segunda Pandemia que a Peste Negra iniciara meio milénio antes, desperta uma corrida para identificar o agente patogénico responsável pela doença. Em 1894, com dias de intervalo, Alexandre Yersin, microbiólogo suíço enviado pelo Instituto Pasteur para Hong Kong, e o bacteriologista japonês Kitasato Shibasaburō, com ligações ao Instituto Robert Koch, descobrem o agente patogénico responsável pelas diversas formas de peste, um bacilo. A primazia acabou por ser reconhecida a Yersin e, depois de algumas flutuações, foi definitivamente batizada em sua honra como Yersinia pestis (Slack, 2012, p. 4-6).

Quando Yersin revela a existência do bacilo da peste, rapidamente se assume que se trata do mesmo agente patogénico responsável pelas pestes do passado, incluindo a infame Peste Negra. Por essa altura, ainda a historiografia portuguesa sobrevivia sobretudo do trabalho isolado de uma mão cheia de pensadores notáveis como Alberto Sampaio, Henrique da Gama Barros ou António da Costa Lobo, para quem as referências a peste estavam longe de constituir um ponto de análise fundamental. Mantinha-se assim a primazia dos médicos entre aqueles que produziam reflexões históricas sobre fenómenos epidémicos passados, ainda que estas sejam, neste período, breves e complementares aos trabalhos sobre as novidades do tema.

Paralelamente, a historiografia médica desenvolvia-se com alguma pujança, tendo no médico e lente portuense Maximiano Lemos o seu representante mais destacado. Autor da primeira síntese de história da medicina em Portugal (Lemos, 1991), publicada originalmente em 1899, e principal figura do único periódico português exclusivamente dedicado ao tema, os Arquivos de História da Medicina Portuguesa (1886-1896 e 1910-1922), Lemos abordou todos os aspetos da história médica e da saúde em Portugal, organizando a sua síntese por cronologias, subdivididas em temas, incluindo em cada grande divisão temporal um breve capítulo dedicado à epidemiologia. Há uma evolução considerável em relação às antigas tentações de romancear ou generalizar abusivamente os diagnósticos retrospetivos de peste, ou sequer de assumir que a referência a eventuais mortalidades elevadas se tratava de surtos de doenças epidémicas, como no caso de uma enigmática mortandade do início de Duzentos (Lemos, 1991, pp. 61-62). É difícil dizer se estas opções se devem à identificação da $Y$. pestis poucos anos antes, mas o autor não o esclarece. Referindo-se à Peste de 1348, segue de perto, com maior comedimento, as referências e fontes de Vieira Meireles, incluindo a hipótese da origem egípcia da doença, não utilizando ainda a expressão que ficará associada 
a esse fenómeno epidémico específico (Peste Negra). Em momento algum parece que António da Cunha Vieira de Meireles ou Maximiano Lemos tenham lido Hecker ou tido um conhecimento relevante da sua obra em segunda mão. Contudo, o espírito era semelhante, ainda que o resultado não tivesse sido tão consistente nem influente. Ao longo de todo um século depois de Vieira Meireles, a historiografia médica, com novas sínteses sem grande novidade, limitava-se a replicar Vieira Meireles, filtrado ou não por Maximiano Lemos (como é o caso da História da Medicina Portuguesa de M. Ferreira de Mira, de 1948). Há, contudo, uma exceção: Ricardo Jorge.

A ação de Ricardo Jorge na identificação, tratamento e contenção do surto de peste bubónica que eclodiu no Porto é famosa, tendo essa experiência permitido ao médico portuense transformar-se numa das autoridades europeias em epidemiologia mais respeitadas (Jorge, 1899). Ricardo Jorge, de resto, produziu, ao longo das primeiras quatro décadas do século XX, bibliografia relevante sobre o estado da arte da peste (Jorge, 1926; 1937; Gaud \& Jorge, 1933), sobre epidemias históricas (Jorge, 1932; 1933; 1935), mas também sobre medidas profiláticas e novas ocorrências no território português ou das então colónias portuguesas (Jorge, 1935a; 1935b), uma empreitada intimamente associada aos seus cargos de médico municipal do Porto (1891-1899), diretor-geral de saúde (1911-1928) e membro do comité permanente da Organização de Higiene da Sociedade das Nações (OHSDN), para o qual foi eleito em meados dos anos de 1920 (Saavedra, 2014, p. 94). Mais do que fazer uma recensão extensa à obra de Ricardo Jorge, importa, neste contexto, sublinhar como dominava o estado da arte da bacteriologia e da epidemiologia da época, agindo em contexto de epidemia e em tempo real mantendo vasta comunicação com os seus colegas internacionais mais notáveis e, sobretudo, como relacionava o conhecimento do presente com as epidemias do passado, às quais devotou parte da sua obra, e que incluía com frequências nas reflexões sobre os problemas epidemiológicos do seu presente.

Sendo então a história da medicina e da saúde temas da lavra dos profissionais da cura, vale a pena comparar as abordagens de Ricardo Jorge e de Maximiano Lemos, médicos da mesma geração (Jorge nasceu em 1858, Lemos em 1860), formados pela mesma escola (a Escola Médico-Cirúrgica do Porto, futura FMUP), lentes na mesma (o primeiro a partir de 1880, o segundo a partir de 1889), tendo ambos lecionado, por exemplo, Medicina Legal. Lemos prefere uma abordagem clássica, focada na medicina enquanto domínio do saber perfeitamente definido, com correntes de conhecimento, práticas e figuras cimeiras em destaque. Já Ricardo Jorge privilegia uma história da saúde, relacionando o passado e o presente em permanência, percebendo que os avanços mais recentes do conhecimento científico 
permitem dar respostas não só ao presente e à prevenção ou contenção de fenómenos futuros, mas também ao longo historial de fenómenos afins que povoam o passado, que interferiram e condicionaram gravemente muitas sociedades, e que conduziram milhões à sepultura de forma prematura. Recorre à história como domínio do conhecimento válido por si, mas também como ferramenta para uma compreensão mais correta do presente.

Poder-se-ia julgar que o interesse português no tema teria nascido com a erupção pestífera que ocorreu no Porto em 1899. Porém, a produção científica antecede esse evento: uma dissertação inaugural da Escola Médico-Cirúrgica do Porto - a primeira de várias que aqui se analisará -, da autoria de Joaquim José Pinto (1897), intitula-se Breves Considerações sobre a Peste Bubónica, fazendo uso pleno daquilo que era então o estado da arte na matéria, incluindo a narração da descoberta quase simultânea de Yersin e Shibasaburō. Interessa particularmente a recensão histórica que o autor faz. Apresentando ainda a lista clássica de epidemias históricas - incluindo várias que, como o próprio reconheceu, tinham a sua natureza pestífera já colocada em causa por diversos autores (Pinto, 1897, p. 24-29) - aborda a Peste Negra entre outras, sem lhe conferir grande destaque, mas não deixa de referir que "É nos meados do século 14 que a peste toma um caracter pandemico pronunciado", descrevendo depois as possíveis rotas de propagação da pandemia com uma atualidade notável (Pinto, 1897, p. 29), enquanto que, como foi dito, Maximiano Lemos, em 1899, ainda apostará numa clássica origem egípcia deste mal. Portugal merece um apartado completo, mas o então jovem médico recorre exclusivamente a Vieira Meireles (Pinto, 1897, p. 32-39), apesar de a natureza infeciosa da peste e de outras doenças ter já tornado obsoletas muitas das observações feitas pelo lente coimbrão poucas décadas antes. Joaquim José Pinto diz no início desse apartado faltarem documentos para se saber mais sobre o flagelo em Portugal - os clínicos que se vinham interessando pelo tema podiam, à data, pouco mais do que folhear algumas coleções documentais já publicadas e crónicas editadas. Os arquivos históricos permaneciam largamente inexplorados (e desorganizados), e sempre de difícil acesso até mesmo aos historiadores a tempo parcial que então constituíam a elite da arte em Portugal. Uma conclusão poderá ser já avançada: se os historiadores estavam ainda longe de demonstrar interesse ou possuir meios para dedicarem trabalhos de fôlego a estas matérias, os clínicos portugueses mais jovens acompanhavam o estado da arte da microbiologia e da epidemiologia internacionais, incluindo nos seus anos de formação.

Vale a pena sair do universo académico por momentos, para que se possa entender quão rapidamente as novas descobertas científicas chegavam também aos leitores da imprensa generalista do final do século XIX - que constituíam uma 
minoria, é certo, mas uma minoria relevante e com uma influência social e económica inversamente proporcional à sua dimensão: resgatando um único exemplo, meramente ilustrativo, refira-se o caso do Comércio de Guimarães, periódico generalista local, criado em 1884 e ativo até hoje. No seu número 1174, de 25 de janeiro de 1897, dá conta das notícias sobre peste bubónica em França, aproveitando a notícia para fazer uma nota histórica sobre a "peste negra" que assolou a Europa na Idade Média e um resumo da descoberta do bacilo três anos antes por Yersin e Kitasato, exortando o governo a agir preventivamente, antes que a doença pudesse regressar a Portugal. Demonstra-se assim que estas informações podiam circular num periódico local perfeitamente alheio aos círculos académicos habituais.

Regressando aos trabalhos de finalistas da Escola Médico-Cirúrgica do Porto, o rol de dissertações inaugurais dedicadas à peste no Porto é maior, mas as que se sucedem à de Joaquim José Pinto são já produto da reação ao surto portuense de 1899. Duas são reações quase imediatas: A Peste do Porto de 1899, de Carlos Alberto da Cunha Coelho (1900) e Pneumonia Pestosa (A Peste Bubonica no Porto - 1899-1900) de António Balbino Rego (1900). A primeira, global e focada na atualidade de então, faz referências episódicas às pestes que no passado assolaram o Porto (Coelho, 1900, p. 47), revelando o habitual conhecimento de ponta no que toca ao agente patogénico; a segunda, dedicada à forma pneumónica da peste, faz apenas uma retrospetiva histórica muito breve sobre a pneumonia pestosa, avançando para a análise dos casos identificados na epidemia portuense (Rego, 1900, p. 39-41). A urgência da atualidade secundarizava - mas não desprezava - a reflexão histórica sobre o tema, domínio que ainda pertencia nestes temas, como se vem dizendo, sobretudo aos homens cujo ofício era o da cura dos corpos, e não o do estudo e reconstituição do passado.

Vale ainda a pena referir a dissertação inaugural de António Xavier da Rocha Pinto (1901), natural da então Índia Portuguesa, o que, tal como o próprio esclarece, motivou a redação de $A$ Peste da India. Ligeiros Apontamentos para a sua Historia. Referindo apenas alguns episódios de peste ocorridos nos territórios portugueses no subcontinente indiano, concentra-se nas epidemias locais da Terceira Pandemia.

Enfim, outras duas dissertações, mais tardias, merecem destaque. Peste bubónica. Etiologia e prophylaxia segundo as modernas acquisições. A Campanha dos Açores. Trabalhos do Porto, de Carlos Maciel Ribeiro Fortes (1910) e, integrando a peste entre outras zoonoses, O Homem e os animais domésticos nas suas relações patológicas, de João M. Moutinho de Gouveia (1915). O trabalho de Ribeiro Fortes é o mais exaustivo entre todas as dissertações aqui referidas, fazendo uma descrição crítica da evolução dos conhecimentos sobre a peste na década e meia anterior, revelando um conhecimento vasto e atualizado daquilo que era a 
ciência de ponta sobre o tema na época. É um contributo muito importante por procurar provar o estabelecimento de um pequeno foco enzoótico de peste no Porto, após 1899, tentando demonstrar que micro-surtos diversos nos anos seguintes terão o Porto como origem. Esta hipótese, que tanto a ciência como a historiografia portuguesa parecem ter ignorado, altera significativamente o que se sabe e pensa sobre a dinâmica da doença, contestando a Bubónica do Porto de 1899 enquanto evento efémero (Fortes, 1910, nota prévia não paginada). Por outro lado, é também importante pelos paralelismos que permite traçar com fenómenos análogos anteriores, no mesmo território e noutros próximos, abrindo caminho a hipóteses nunca antes abordadas, como a eventual existência de um foco silvestre de peste em Portugal ao longo da Segunda Pandemia (Silva, 2021, pp. 595-602). Por fim, a dissertação de Moutinho de Gouveia demonstra que no plano das zoonoses, como grande grupo de infeções do qual a peste é uma das mais destacadas, a peste é uma doença com potencial para atingir muitas outras espécies de mamíferos, ainda que com gravidade distinta.

Após o verdadeiro surto de dissertações portuenses dedicadas ao tema, com as respetivas recensões históricas, o interesse médico esmorece em Portugal, e o dos historiadores leva anos a surgir. Durante a fase final da Primeira República e do período de Ditadura Militar e Estado Novo que se seguiu, a bibliografia portuguesa sobre o tema manteve-se exígua. A redefinição de interesses prioritários por parte dos médicos-historiadores como Luís de Pina ou J. A. Pires de Lima, focados nos grandes vultos da arte ou em traçar os antecedentes de especialidades, limita consideravelmente o contributo dos profissionais da cura para o tema.

Ainda entre os historiadores que fizeram a transição do século XIX para o XX, Henrique da Gama Barros foi aquele que mais (e mais informadas) referências fez ao flagelo da peste, e da Peste Negra em concreto. Percebendo o impacto do fenómeno, e fazendo uso daquela que então seria a bibliografia nacional e internacional consagrada - falo de Vieira Meireles e de Francis Aidan Gasquet Gama Barros não tem necessidade de discutir a natureza da doença no contexto da sua obra sobre a história institucional e administrativa do Portugal Medieval (Barros, 1948, V, pp. 125-148 e 165-186), a sua História da Administração Pública em Portugal dos séculos XII a XV, editada originalmente em 4 tomos, entre $1885 \mathrm{e}$ 1922, e reeditada nos anos de 1950, com comentários e anotações de Torcato de Sousa Soares. A lista de epidemias de Vieira Meireles - ainda que a sua análise "nosogeográfica" estivesse já ultrapassada -, e as cores obscuras emprestadas por Gasquet foram suficientes para o propósito. São essas mesmas 'cores' às quais Virgínia Rau recorre em 1946 para entregar à Peste Negra e às suas sucessoras o trono entre os fatores de desestabilização do século XIV no seu Sesmarias 
Medievais Portuguesas (reeditado em 1982), sendo Gasquet a principal influência, mais de meio século após a publicação original da obra do eclesiástico inglês.

Constituindo um exemplo curioso, vale a pena falar de uma lista local de epidemias: enquanto procurava replicar o modelo dos Portugaliae Monumenta Historica à escala vimaranense, com os Vimaranes Monumenta Historica, cuja publicação se iniciou em 1908 (Guimarães, 1932), João Gomes de Oliveira Guimarães, comummente conhecido pelo seu cargo eclesiástico de Abade de Tagilde, aproveitou muitos testemunhos sobre epidemias históricas, recolhidos ao longo do seu extraordinário labor com fontes documentais inéditas vimaranenses, para elaborar um artigo em três partes dividido por dois números da Revista de Guimarães (1906; 1906a; 1907) que replica também à escala local o labor de Vieira Meireles quarenta anos antes. Recorrendo assim aos modelos tradicionais de descrição cronológica de diversas epidemias, o grande contributo do Abade de Tagilde passa precisamente pelo uso de documentação inédita - o que nenhum dos autores anteriores fez nesta escala - reunindo testemunhos coevos de diversos fenómenos epidémicos que afetaram Guimarães, da Idade Média até ao final do século XVIII, e onde se inclui, naturalmente, a Peste Negra.

Do lado da emergente classe de historiadores profissionais, produzidas pelas Faculdades de Letras nascidas com o advento da República e pelos organismos estatais novos ou renovados, como os arquivos distritais, conta-se um par de opúsculos ao longo de décadas (Baião, 1942; Rau, 1966); mas as monografias dedicadas à Peste Negra em certas cidades, regiões ou reinos, focadas sobretudo em análises demográficas e socioeconómicas, estavam manifestamente afastadas daquilo que eram as correntes dominantes da historiografia portuguesa durante a ditadura.

É precisamente a já referida Virgínia Rau que ajuda a lançar as sementes daquilo que será feito nas primeiras décadas do terceiro e último período aqui analisado, através da projeção concedida a um discípulo, António Henrique de Oliveira Marques. Oliveira Marques produziu, em poucos anos, obras marcantes da historiografia portuguesa que constituem leituras obrigatórias até hoje, ainda que se encontrem datadas em muitos aspetos. Uma dessas obras, A Sociedade Medieval Portuguesa, cuja origem estava na sua dissertação de licenciatura, de 1956, sendo originalmente publicada em 1964 e reeditada cinco vezes, a última das quais em 2010, dedicou um capítulo à saúde, higiene e corpo. Inovador na abordagem, o conteúdo relacionado com as doenças, e a peste em particular, é curto e largamente devedor de Vieira Meireles (Marques, 2010, pp. 121-122 e 274). Estas referências eram as possíveis e cumpriram os objetivos que a obra teria em 1956 ou em 1964, mas o recurso, por vezes descuidado, que ainda hoje se faz desse capítulo acabou por arrastar até ao presente a lista de epidemias de Vieira Meireles que, com século e 
meio, é ainda utilizada amiúde através do filtro de Oliveira Marques. Assim, se Virgínia Rau pinta a Peste Negra com os tons que Gasquet definiu em 1893, ainda em 1946, Vieira Meireles nunca desapareceu do radar dos medievalistas portugueses.

É também um trabalho coordenado por Oliveira Marques e integrando diversos estudantes - todos eles futuros historiadores consagrados - que inaugura a análise socioeconómica da Peste Negra em Portugal (Marques et al., 1963), ainda que, uma vez mais, a integração de elementos não-humanos e sobre a natureza da doença não ocupassem ainda um lugar de relevo. A profícua parte inicial da carreira de Oliveira Marques foi interrompida depois de ter caído em desgraça junto do regime, adiando década e meia a concretização daquilo que definiu como o seu programa de história económica medieval portuguesa, possível apenas após o estabelecimento da Democracia em Portugal (Barata \& Henriques, 2011, pp. 260-271).

Naturalmente, houve algumas abordagens distintas à questão da Peste Negra, mas foram sempre casos isolados (como Tunhas, 1965). A produção historiográfica internacional das décadas de 60 e 70 do século XX, onde se destacam tanto obras de cariz puramente académico ${ }^{2}$, como sólidas sínteses de divulgação que ainda hoje constituem leituras válidas (acima de todos, Ziegler, 1982 [edição original de 1969]), demonstram a evolução do tema e aplicação constante de novas abordagens que, em Portugal, era ainda apenas modestamente replicada.

\section{O reencontro da historiografia portuguesa com a Peste Negra e com o estado da arte das ciências biomédicas (1974-2021)}

O corte feito em 1974 não responde a um critério de rutura internacional na ciência ou na historiografia da peste, mas a um critério interno, nacional, provocado pelas decisivas mudanças políticas ocorridas em Portugal. A renovação temática da historiografia portuguesa sobre a Idade Média no último quartel do século XX, com reflexos evidentes no que foi produzido sobre Peste Negra, está intimamente ligada à democratização oferecida pelo 25 de abril de 1974. A fundação da Universidade Nova de Lisboa (UNL) e da sua Faculdade de Ciências Sociais e Humanas (FSCHUNL), constituiu um momento de renovação, ampliado pelas novas gerações de docentes nas pré-existentes Faculdades de Letras das Universidades do Porto, Coimbra e Lisboa. Esta renovação também favoreceu, ainda que indiretamente, o estudo da Peste Negra e das pestes históricas em geral. Oliveira Marques, fundador da UNL, pôde por fim concretizar o seu 'programa', e uma vaga de dissertações dos novos cursos de mestrado e teses de doutoramento em história urbana e em

\footnotetext{
${ }^{2}$ Tratando-se de uma bibliografia inesgotável, refira-se apenas um quarteto de obras clássicas que considero estruturantes até hoje, em domínios distintos, e isto tendo em conta apenas livros, e não artigos: Carpentier (1962); Biraben (1975-1976); Dols (1977); Meiss (1978).
} 
história rural permitiu análises integrais de territórios mais ou menos circunscritos, com inquéritos bem definidos, mas amplos, acabando por revelar o impacto de fenómenos diversos, entre os quais emerge a peste ${ }^{3}$. Esta tendência acabou por ser replicada nas restantes faculdades, com resultados igualmente relevantes.

Porém, constituindo estas monografias importantes e decisivos contributos para o conhecimento do Portugal Medieval, as doenças epidémicas constituíam um tópico entre muitos, secundário e quase acidental. Não era o propósito desses trabalhos, e não se poderia exigir que colmatassem as lacunas que, por exemplo, vinham sendo preenchidas também no país vizinho ${ }^{4}$. Entre os trabalhos de fôlego que também acolhiam a peste, houve mais opúsculos dedicados à Peste Negra, mas por norma sobre um estudo de caso de um documento, indivíduo ou acontecimento (Moreno, 1978; 1983; 1996; Coelho, 1980; Carvalho, 1985; Barroca, 2003).

Tal como a dissertação de António Tunhas anos antes, há neste período uma singular obra dedicada totalmente às pestes históricas, produzida por Mário da Costa Roque (1979) como estudo introdutório à sua edição do Regimento Proveitoso contra toda a Pestenença, e que recorria, de facto, ao que de mais atual havia então na ciência da peste para analisar as suas ocorrências históricas. Outras pestes, sobretudo no contexto pós-medieval, têm recolhido atenção de investigadores diversos, com destaque para Laurinda Abreu e para os séculos XVIXVIII, mas constituindo sempre exceções.

No plano internacional, as últimas décadas do século XX e a primeira do atual são marcadas por um intenso debate sobre a verdadeira natureza das pestes históricas, anteriores à terceira pandemia iniciada em meados do século XIX, em especial da célebre Peste $\mathrm{Negra}^{5}$. Esse longo debate foi encerrado com a confirmação dada pela arqueologia molecular e pela paleogenómica de que a Peste Negra foi de facto provocada por epidemias massivas de infeções por Y. pestis, tendo sido possível descodificar o genoma da bactéria medieval e provar as semelhanças com as formas atuais do bacilo (Bos et al., 2011). Toda a bibliografia

\footnotetext{
${ }^{3}$ A lista é longa e totalizaria algumas dezenas de títulos. Opto assim por citar apenas aquelas que oferecem mais indícios sobre o impacto da Peste Negra: Coelho (1989); Beirante (1995); Rodrigues (1995); Ferreira (2010).

${ }^{4}$ Também aqui a lista é longa, mas vale a pena destacar uma dezena de trabalhos de fundo sobre a Peste Negra e as suas sucessoras no território do atual Estado Espanhol, cobrindo praticamente todos os antigos reinos ibéricos, com exceção de Portugal: Verlinden (1938); López de Meneses (1951); Cabrillana (1968); Sobrequés Callico (1970-71); Ubieto Arteta (1975); Rubio (1979); Vaca Lorenzo (1984); Amasuno (1994); Monteano (2001); Ruiz de Loizaga (2009).

${ }^{5}$ Trata-se de um debate longo, com muitas matizes, que durou décadas e chegou a atingir proporções quase violentas. Mais do que dissecar essa questão, o que constituiria um exercício fútil neste contexto, remeto para uma síntese sobre o problema, elaborada pouco antes do seu 'encerramento', no qual a autora chega a separar as duas fações designando-os por "sceptics" (céticos) e "believers" (crentes). Aproveitando esse texto e a sua condição de open access, remeto para o resumo nele contido, sobre essa historiografia "cética", para mais leituras e autores (Nutton, 2008).
} 
portuguesa - e boa parte da espanhola - citada sobre o tema é anterior, ou esteve alheia a este debate fundamental. Em momento algum, esta observação deve ser entendida como uma menorização do esforço de construção de uma historiografia sólida e rigorosa que é a regra das últimas décadas em Portugal. Mas é também verdade que Portugal é parte de uma realidade alargada, e o contributo dos historiadores portugueses - ou que trabalhem sobre Portugal - é necessário e urgente para a constituição de uma imagem rigorosa do impacto destes fenómenos no passado. O estudo da Peste Negra, de outras pestes históricas ou ainda outras doenças historicamente importantes, é indispensável para a construção de uma narrativa realista do passado. O tempo de pandemia que se vive hoje não torna esse labor mais urgente - torna-o, isso sim, mais evidente.

Esta era de renovação dos trabalhos sobre a peste, e sobre a Peste Negra, a Peste de Justiniano e outras pestes históricas, tem permitido globalizar a análise dos impactos (Green, 2014), trazer para o debate espaços negligenciados até recentemente (Chouin, 2018; Green, 2018) e cruzar de forma integrada história ambiental, climática, e história económica e social, abrindo caminhos que antes pareciam ficção científica (Campbell, 2016). Se a peste em particular não recolheu nestas décadas o mesmo interesse por parte da cada vez maior e mais consolidada comunidade científica portuguesa, fruto de prioridades distintas das ciências biomédicas, não se poderá dizer que o conhecimento não circula em permanência e que haverá algum tipo de desfasamento temporal entre aquilo que é estudado e publicado, e aquilo que é conhecido em Portugal. O trabalho em rede e tecnologias tão decisivas como a internet permitiram o esbatimento total desses lapsos que em tempos podiam ser consideráveis. A pandemia de COVID 19 será, por certo, capaz de despertar o interesse dos historiadores portugueses para os fenómenos análogos do passado, e a Peste Negra não será uma exceção, como alguns sinais têm já revelado (Coelho, 2020; Silva 2021)

\section{Conclusão}

Estabelecendo a História e a Historiografia como eixo de análise, creio que é importante perceber como evoluiu o conhecimento de uma doença no passado, em particular da mais devastadora entre as suas manifestações documentadas, à luz da evolução do conhecimento presente sobre a própria doença.

Ao longo dos últimos dois séculos, os avanços científicos sobre a peste têm chegado a Portugal rapidamente, havendo espaço para que investigadores portugueses possam contribuir para esse avanço e participar nos debates mais atuais, como revela de forma eloquente o exemplo de Ricardo Jorge. Porém, sendo uma doença com uma influência muito importante na evolução das sociedades 
humanas do Velho Mundo, nem sempre os historiadores portugueses, a quem as dificuldades próprias do desenvolvimento e estabelecimento de um ofício constituíam um obstáculo extra, souberam acompanhar estas novidades e, mais decisivo, integrá-las nas suas investigações.

O historiador não é um elemento passivo no desenvolvimento da ciência da peste e de outras doenças historicamente impactantes. Tal como Ricardo Jorge demonstrou, uma vez mais, além da importância per si do conhecimento rigoroso e amplo do passado, a epidemiologia histórica é também uma arma no combate aos flagelos análogos do presente e do futuro, preparando, fornecendo termos de comparação e cenários reais e completos. Os historiadores atuais, mais preparados e mais integrados num crescente meio científico estruturado, institucionalizado e global do que qualquer um dos seus pares do passado, devem assumir uma posição ativa nos debates sobre as epidemias do passado, empregando a crítica histórica de documentos escritos e não-escritos, colaborando - e não competindo ou se sobrepondo - a biólogos, epidemiologistas e cientistas biomédicos.

A ciência da peste nasce e consolida-se com a reemergência da doença na segunda metade do século XIX, enquanto a historiografia da peste já havia sido inaugurada na primeira metade desse século, motivada pela ocorrência de outros, novos fenómenos pandémicos. Ambas nascem como necessidades e respondendo a fenómenos presentes, tornando-se matéria do conhecimento geral, do senso comum e do imaginário coletivo. Um conhecimento rigoroso e amplamente divulgado desfaz mitos, combate rumores e abre caminho à aplicação mais consensual e informada de soluções urgentes para problemas emergentes. Ontem, como hoje, os representantes das Ciências da Vida e das Ciências Humanas devem trabalhar em rede, constituindo esse trabalho uma missão confiada pelas comunidades e uma necessidade que deve ser encarada positivamente, em Portugal, como no resto do mundo.

\section{Referências}

A peste bubonica (1897, 25 de janeiro). Commercio de Guimarães.

Amasuno, M. V. (1994). Cronología de la peste en la corona de Castilla durante la segunda mitad del siglo XIV. Studia historica. Historia medieval 12, 25-52.

Archivos de Historia da Medicina Portugueza. Porto. 1886-1896; 1910-1922.

Baião, A. (1942). As Freiras de Lorvão e a Peste de 1348. Instituto, 100, 734-737.

Barata, F. T., \& Henriques, A. C. (2011). Economic and Fiscal History. In José Mattoso (dir.), Maria de Lurdes Rosa, Bernardo Vasconcelos e Sousa, Maria 
João Branco (coords.), The Historiography of Medieval Portugal. C. 19502010 (pp. 261-281). Instituto de Estudos Medievais.

Barroca, M. J. (2003). A peste negra na epigrafia medieval portuguesa. In L. A. da Fonseca, L. C. Amaral, M. F. F. Santos (coord.), Os Reinos Ibéricos na Idade Média: livro de homenagem ao Professor Doutor Humberto Carlos Baquero Moreno (vol. 3, pp. 1159-1166). Universidade de Porto. Faculdade de Letras.

Barros, Henrique da Gama (1945-1954). História da Administração Pública em Portugal dos séculos XII a XV. $2^{\mathrm{a}}$ edição dirigida e comentada por Torcato de Sousa Soares. 1945-1954. 11 tomos. Livraria Sá da Costa.

Beirante, M. A. R. (1995). Évora na Idade Média. Fundação Calouste Gulbenkian, Junta Nacional de Investigação Científica.

Biraben, J.-N. (1975-1976). Les hommes et la peste en France et dans les pays européens et méditerranéens. 2 vols. Mouton.

Biraben, J.-N. (1989). Essai sur les réactions des sociétés éprouvées par de grands fléaux épidémiques. In N. Bulst et R. Delort (éd.), Maladie et société XII e XVIII e siècles (pp. 367-374). Editions du CNRS.

Bos, K. I., Schuenemann, V. J., Golding, G. B., Burbano, H. A., Waglechner, N., Coombes, B. K., McPhee, J. B., DeWitte, S. N., Meyer, M., Schmedes, S., Wood, J., Earn, D. J., Herring, D. A., Bauer, P., Poinar, H. N., \& Krause, J. (2011). A draft genome of Yersinia pestis from victims of the Black Death. Nature, 478(7370), 506-510. https://doi.org/10.1038/nature10549

Cabrillaña, N.(1968). La crisis del siglo XIV en Castilla: la peste negra en el obispado de Palencia. Hispania 109, 245-258.

Campbell, B. M. S. (2016). The Great Transition. Climate, Disease and Society in Late-Medieval World. Cambridge University Press.

Carpentier, E. (1962). Une ville devant la Peste. Orvieto et la Peste Noire de 1348. École Pratique des Hautes Études - VIe section; Centre de Recherches Historiques.

Carvalho, S. L. (1985). A Peste de 1348 em Sintra. In Actas das Jornadas de História Medieval «1383-1385» e a Crise Geral dos Séculos XIV-XV (pp. 129135).

Chouin, G. (2018). Reflections on plague in African history (14th-19th c.). Afriques, 9. https://doi.org/10.4000/afriques.2228

Coelho, C. A. C. (1900). A Peste do Porto de 1899. [Dissertação inaugural apresentada à Escola Médico-Cirúrgica do Porto]. http://hdl.handle.net/10216/17146

Coelho, M. H. C. (1980). Um Testamento Redigido em Coimbra no Tempo da Peste Negra. Revista Portuguesa de História XVIII, pp. 312-331.

Coelho, M. H. C. (1989). O Baixo Mondego nos Finais da Idade Média. 2 volumes. Imprensa Nacional-Casa da Moeda. 
Coelho, M. H. C. (2020). 1348. Peste Negra: o flagelo que foi quase "global". In Carlos Fiolhais, José Eduardo Franco, José Pedro Paiva (dirs.), História Global de Portugal (pp. 269-275). Temas e Debates.

Dols, M. W. (1977). The Black Death in the Middle East. Princeton University Press.

Ferreira, M. C. F. (2010). Guimarães: «duas vilas, um só povo»: Estudo de história urbana (1250-1389). CITCEM.

Fortes, C. M. R. (1910). Peste bubónica. Etiologia e prophylaxia segundo as modernas acquisições. A Campanha dos Açores. Trabalhos do Porto. [Dissertação inaugural apresentada à Escola Médico-Cirúrgica do Porto]. https://hdl.handle.net/10216/16804

Gaud, M., \& Jorge, R. (1933). Sur l'importance du bubon sous-pectoral dans le diagnostic et l'évolution de la peste. Bulletin mensuel de l'office international d'hygiene publique, $X X V(1)$.

Gouveia, J. M. M. (1915). O Homem e os animais domésticos nas suas relações patológicas. [Dissertação inaugural apresentada à Escola Médico-Cirúrgica do Porto].

Green, M. H. (2014). Taking "Pandemic" seriously: making the Black Death global. The Medieval Globe 1, 27-61.

Green, M. H. (2018). Putting Africa on the Black Death map: Narratives from genetics and history. Afriques 9. https://doi.org/10.4000/afriques.2125

Grmek, M. D. (1995). Introduction. In Mirko D. Grmek (Dir.), Histoire de la pensée médicale en Occident. 1 - Antiquité et Moyen Âge (pp. 7-24). Edition du Seuil.

Guimarães, J. G. O. (1906). As Epidemias em Guimarães. I Parte. Revista de Guimarães, 23(2), 52-58.

Guimarães, J. G. O. (1906a). As Epidemias em Guimarães. II ${ }^{a}$ Parte. Revista de Guimarães, 23(3-4), 108-114.

Guimarães, J. G. O. (1907). As Epidemias em Guimarães. III ${ }^{a}$ Parte. Revista de Guimarães, 24(3-4), 123-132.

Guimarães, J. G. O. (ed.) (1932). Vimaranis Monumenta Historica: a saculo nono post Christum usque ad vicesimum. 2 vols. Vimaranensis Senatus.

Jorge, R. (1899). A Peste bubonica no Porto - 1899. Seu descobrimento-Primeiros trabalhos. Repartição de Saude e Hygiene da Camara do Porto.

Jorge, R. (1926). Les pestilences et la Convention Sanitaire Internationale. Arquivos do Instituto Central de Higiene, 3(1), 1-107.

Jorge, R. (1932). Les anciennes épidémies de peste en Europe, comparés aux épidémies modernes. Imprensa Nacional. 
Jorge, R. (1933). Summa epidemiologica de la peste : épidémies anciennes et modernes. Bulletin mensuel de l'office international d'hygiene publique, $X X V .3$.

Jorge, R. (1935). Regimento Proveitoso contra a Pestenença: Lisboa, Valentim Fernandes 1496 (?). Clínica, Higiene e Hidrologia 1, 4-7.

Jorge, R. (1935a). La Peste en Angola. Bulletin mensuel de l'office international d'hygiene publique, XXVII(2).

Jorge, R. (1935b). La Peste Africaine. Rapport présenté au comité permanente de l'Office International d'Hygiène Publique. Supplément au Bulletin mensuel de l'office international d'hygiene publique, XXVII(9).

Jorge, R. (1937). Les rodentia domestiques et sauvages dans l'evolution séculaire et mondiale de la peste. In Extrait des Comptes Rendus du XIIe Congrès International de Zoologie - Lisbonne, 1935. Casa Portuguesa.

Kriehn, G. (1909). The Black Death of 1348 and 1349. By FRANCIS AIDAN GASQUET, D.D., Abbot President of the English Benedictines. Second Edition. (London: George Bell and Sons. 1908. Pp. xxv, 272.). The American Historical Review 14(3), 569-570. https://doi.org/10.1086/ahr/14.3.569

Lemos, M. (1991). História da Medicina em Portugal. Doutrinas e Instituições. $2^{\text {a }}$ edição, prefácio de Maria Olivia Rúber de Meneses. Publicações Dom Quixote, Ordem dos Médicos [1 $1^{\mathrm{a}}$ edição, 1899].

López de Meneses, A. (1951). Documentos acerca de la peste negra en los dominios de la Corona de Aragón. Estudios de Edad Media de la Corona de Aragón 6, 291-447.

Marques, A. H. O. (2010). A sociedade medieval portuguesa-Aspectos de vida quotidiana. $6^{\mathrm{a}}$ edição. A Esfera dos Livros. [1 $1^{\mathrm{a}}$ edição de 1956].

Marques, A. H. O. (dir.), Gonçalves, Iria; Moreno, Humberto Carlos; Ramos, Luís Oliveira (1963). Para o Estudo da Peste Negra em Portugal. Apresentação de Virgínia Rau. Separata de Bracara Augusta, 14-15(1-2).

Meireles, A. C. V. (1866). Memorias da Epidemiologia Portugueza. Imprensa da Universidade de Coimbra.

Meiss, M. (1978). Painting in Florence and Siena after the Black Death. The Arts, Religion, and Society in Mid-Fourteenth Century. Princeton University Press.

Mira, M. F. (1948). História da Medicina Portuguesa. Empresa Nacional de Publicidade.

Moll, I., Salas V., P., \& Pujadas-Mora, J. (2017). Toward a new sanitary modernity: The 1820 plague epidemic in Majorca. Annales de démographie historique, 134, 125-149. https://doi.org/10.3917/adh.134.0125

Monteano, P. J. (2001). La Peste Negra en Navarra: la catástrofe demográfica de 1347-1349. Príncipe de Viana 62(222), 87-120. 
Moreno, H. B. (1978). Um testamento concebido durante a Peste Negra. Bracara Augusta XXXII(73-74) (85-86), 125-141.

Moreno, H. B. (1983). Reflexos da Peste Negra na Crise de 1383-85. Bracara Augusta, XXXVII(83-84), 373-386.

Moreno, H. B. (1996). A Peste Negra e os legados à Igreja. Revista de Ciências Históricas da Universidade Portucalense Infante D. Henrique, VI, 133-143.

Nutton, V. (2008). Introduction. Medical History, 52(S27) [Pestilential complexities: understanding medieval plague.], 1-16. https://doi.org/hjds

Pigeaud, J. (2017). De la difficulté de penser la maladie pestilentielle. Le legs antique. In François Clément (Dir.), Épidémies, épizooties. Des représentations anciennes aux approches actuelles (pp. 15-27). Presses Universitaires de Rennes.

Pinto, J. J. (1897). Breves Considerações sobre a Peste Bubonica. [Dissertação inaugural apresentada à Escola Médico-Cirúrgica do Porto]. http://hdl.handle.net/10216/17244.

Rau, V. (1966). Un document portugais sur la peste noire de 1348. Annales du Midi : revue archéologique, historique et philologique de la France méridionale, 78(77-78), 331-334.

Rau, V. (1982). Sesmarias Medievais Portuguesas. $2^{\mathrm{a}}$ edição. Editorial Presença [1 ${ }^{\mathrm{a}}$ edição: 1946].

Rawcliffe, C. (2010). The concept of health in medieval society. In Simonetta Cavaciocchi (ed.), Le interazioni fra economia e ambiente biologico nell'Europa preindustriale (pp.317-334). Firenze University Press.

Pinto, A. X. R. (1901). A Peste da India: ligeiros apontamentos para a sua história. [Dissertação inaugural apresentada à Escola Médico-Cirúrgica do Porto]. https://hdl.handle.net/10216/17095

Rego, A. B. (1900). Pneumonia Pestosa (A Peste Bubonica no Porto - 1899-1900). [Dissertação inaugural apresentada à Escola Médico-Cirúrgica do Porto]. http://hdl.handle.net/10216/61158

Rodrigues, A. M. S. A. (1995). Torres Vedras. A Vila e o Termo nos Finais das Idade Média. Fundação Calouste Gulbenkian. Junta Nacional de Investigação Científica e Tecnológica.

Roque, M. C. (1979). As pestes medievais europeias e o "Regimento Proueytoso contra ha Pestenença". Fundação Calouste Gulbenkian.

Rubio, A. (1979). Peste negra, crisis y comportamientos sociales en la Espana del siglo XIV: La ciudad de Valencia (1348-1401). Universidad de Granada.

Ruiz de Loizaga, S. (2009). La peste en los reinos peninsulares. Según documentación del Archivo Vaticano (1348-1460). Museo Vasco de Historia de la Medicina y de la Ciencia. 
Saavedra, M. (2014). A Malária em Portugal: Histórias e Memórias. Imprensa de Ciências Sociais.

Silva, A. F. O. (2021). A Peste Negra em Portugal. Os casos do Entre-Douro-eMinho e do Entre-Tejo-e-Odiana. [Tese de Doutoramento em História apresentada à Faculdade de Letras da Universidade do Porto]. https://hdl.handle.net/10216/137710

Slack, P. (2012). Plague: A Very Short Introduction. Oxford University Press.

Sobrequés Callico, J. (1970-1971). La Peste Negra en la Península Ibérica. Anuario de Estudios Medievales, 7, 67-101.

Tunhas, A. J. C. (1965). A peste negra: notas para uma interpretação psico-social. [Dissertação de Licenciatura apresentada à Faculdade de Medicina da Universidade do Porto].

Ubieto Arteta, A. (1975). Cronología del desarrollo de la Peste Negra en la Península Ibérica. In Estudios sobre el Reino de Valencia. Vol. 5 (pp. 47-66). Consejo Superior de Investigaciones Científicas. Instituto "Jerónimo Zurita".

Vaca Lorenzo, A. (1984). La Peste Negra en Castilla. Aportación al estudio de algunas de sus consecuencias económicas y sociales. Studia Historica. Historia Medieval, 2, 89-107.

Verlinden, C. (1938). La grande peste de 1348 en Espagne: contribution à l'étude de ses conséquences économiques et sociales. Revue Belge de Philologie et Histoire, 17, 103-146.

Ziegler, P. (1982). The Black Death. Penguin Books [edição original de 1969]. 